\title{
Cooperação com empresas de base tecnológica: pesquisa-ação no setor elétrico
}

\section{Cooperation network between technology-based enterprises: action-research in the electro-electronic sector}

\author{
José Roberto Tálamo ${ }^{1}$ \\ Marly Monteiro de Carvalho
}

\begin{abstract}
Resumo: A pressão por inovação em empresas de base tecnológica, em ciclos cada vez mais curtos e demandando competências complexas, tem levado as empresas à busca de uma estruturação sob a forma de redes de cooperação empresarial, a fim de mitigar riscos e reduzir custos enquanto acelera o time to market. Entretanto, apesar de todas as vantagens e oportunidades reais, há grandes barreiras a serem transpostas. O objetivo dessa pesquisa é compreender o processo de estruturação de uma rede de cooperação no contexto de empresas de base tecnológica. A abordagem metodológica utilizada foi a pesquisa-ação desenvolvida em 30 empresas do setor eletroeletrônico. Os resultados apontam o temor ao comportamento oportunista como o item mais crítico à formação da rede de cooperação empresarial.

Palavras-chave: Redes de cooperação empresarial. Empresas de base tecnológica. Confiança. Comportamento oportunista.
\end{abstract}

\begin{abstract}
The pressure for short-cycle innovation in technology-based enterprises and the demand for complex competencies have led companies to focus on developing enterprise network cooperation in order to reduce risks and costs, while speeding up time to market. Despite all real advantages and chances, there are great barriers to overcome. The objective of this research is to understand the process of development of a cooperation network between technology-based enterprises. The methodology used was the action-research, which was carried out in 30 companies in the electro-electronic sector. The results indicate that fear of opportunistic behavior is the most critical factor to the development of enterprise network cooperation.
\end{abstract}

Keywords: Enterprise network cooperation. Technology-based enterprise. Trust. Opportunistic behavior.

\section{Introdução}

As empresas de base tecnológica exercem papel fundamental na economia. Além de atuarem como berços de novas tecnologias, impulsionam a economia, o desenvolvimento tecnológico e agregam a maior parcela da mão de obra especializada do mercado (PORTER, 1990).

No entanto, micro, pequenas e médias empresas de base tecnológica sofrem pressão financeira e dificuldade de acesso a capital de risco, além de pressão do mercado por inovações tecnológicas, fator crítico à sua sobrevivência. Além disso, produtos e processos têm se tornado crescentemente sofisticados, exigindo dessas empresas capacitações crescentes para a operacionalização de seus processos produtivos e de P\&D. Estes aspectos redundam em custos crescentes. Uma forma de mitigar essas questões é a estruturação das empresas na forma de redes de cooperação empresarial, com possibilidade de compartilhar a estrutura produtiva e os projetos de desenvolvimentos tecnológicos, de modo a agilizar o time-to-market de novos produtos no mercado e compartilhar custos, tornando-as mais eficientes e eficazes na esfera de lucros. Entretanto, apesar das vantagens, há grandes barreiras a serem transpostas no processo de formação de redes de cooperação.

A atuação no contexto da inovação tecnológica cria uma diferença significativa em relação às demais empresas: a incerteza associada ao padrão tecnológico. A empresa de base tecnológica sofre tanto o risco do insucesso de sua inovação quanto o risco da defasagem tecnológica frente ao mercado, conforme destacam Utterback (1994), Muniz (2000) e Tálamo (2008).

\footnotetext{
${ }^{1}$ Departamento de Engenharia de Gestão, Universidade Federal do ABC - UFABC, Rua Santa Adélia, 146, Sala A 620-1, Bangu, CEP 09210-170, Santo André, SP, Brasil, e-mail: roberto.talamo@ufabc.edu.br

2 Departamento de Engenharia de Produção, Escola Politécnica, Universidade de São Paulo - USP,

Av. Professor Almeida Prado, 128, Travessa 2, Bloco G, 2 andar, CEP 05508-900, São Paulo, SP, Brasil, e-mail: marlymc@usp.br Recebido em 14/1/2011 — Aceito em 17/2/2012

Suporte financeiro: Nenhum.
} 
Estes fatores geram a tendência da especialização, conforme destacam Scott e Storper (1988). Conforme esses autores, além da tendência da especialização, estas empresas apresentam a tendência da aglomeração; duas características fundamentais das empresas de base tecnológica. De fato, estas empresas tendem a atuar em nichos específicos ao mesmo tempo que priorizam a concentração geográfica, estabelecendo várias configurações de agrupamentos empresariais.

As redes de cooperação abrem perspectivas reais ao compartilhamento de conhecimentos e aprendizados, fundamentais no processo da inovação tecnológica. A expressão "rede de cooperação" é abrangente e aplicável a diversas taxonomias de agrupamentos empresariais, no qual ocorrem transações e transferências de produtos, serviços e informações. Além disso, contém aspectos sociais e comportamentais típicos, principalmente quando empresas similares se agrupam em arranjos horizontais, de acordo com a rede objeto deste estudo, conforme destacam Grandori e Soda (1995).

Portanto, a pesquisa objetiva compreender o processo de estruturação de uma rede de cooperação no contexto de empresas de base tecnológica. A abordagem metodológica utilizada foi a pesquisa-ação desenvolvida em empresas fabricantes de instrumentos eletrônicos.

Este artigo está estruturado em seis seções. Na síntese do quadro teórico, apresentada na seção 2 , são explorados os principais aspectos relacionados às redes de cooperação e empresas de base tecnológica. A seção 3 apresenta os aspectos metodológicos aplicados na pesquisa, com uma síntese dos tipos de pesquisa-ação, a modalidade de pesquisa-ação utilizada e um detalhamento do ciclo e etapas componentes da pesquisa-ação. A seção 4 apresenta o detalhamento da abordagem metodológica utilizada na pesquisa. Os resultados da pesquisa são analisados na seção 5, seguida das conclusões descritas na seção 6 .

\section{Cooperação e empresas de base tecnológica: síntese da literatura}

Carvalho et al. (2000), combinando definições do SEBRAE e do OTA (Office of Technology Assesment - Órgão do Congresso Americano gerador de políticas voltadas às pequenas empresas), definem empresa industrial de base tecnológica, como a micro e pequena empresa com até 100 funcionários, comprometida com o projeto, desenvolvimento e produção de novos produtos e/ou processos. Estão baseadas no conhecimento técnico-científico, são usuárias de tecnologias inovadoras, investidoras de elevado percentual de seu faturamento em pesquisa e desenvolvimento, fazem uso sistemático do conhecimento técnico-científico e utilizam-se da mão de obra especializada com atuação voltada a mercados pequenos e específicos.
Há várias definições de redes de cooperação, classificadas em taxonomias, conforme parâmetros legais ou hierárquicos. Storper e Harrison (1991) definem taxonomias baseadas no grau de hierarquia entre os integrantes, classificando as redes em Simétricas ou Flexíveis, Levemente Assimétricas, Assimétricas e Hierárquicas, conforme cresce o grau de assimetria entre a empresa coordenadora (quando existente) e os integrantes.

Grandori e Soda (1995) e Fusco (2005) utilizam tanto a hierarquia quanto a formalização legal para classificar as redes, denominando-as: a) Redes Sociais Simétricas, quando as informações capazes de agregar valor econômico, multiplicar habilidades e difundir aprendizados circulam através de canais exploratórios estabelecidos pelos gestores de cada empresa integrante, sem a presença de instrumentos legais entre os integrantes; b) Redes Sociais Assimétricas, quando o padrão de conexão entre as empresas é igual a redes sociais simétricas, porém com um agente central focado nos objetivos da rede de cooperação, sem qualquer tipo de coordenação sobre cada empresa individualmente. Nesta formação existem contratos legais, porém voltados apenas à definição de bens e serviços trocados entre os integrantes; c) Redes Burocráticas Simétricas, formadas por um grande número de empresas similares, sem que haja uma dependência complexa ou em grau elevado entre os integrantes. Há contratos formais que estabelecem relações, responsabilidades e direitos entre os integrantes, formalizam trocas e acordos entre as partes e protegem os direitos individuais dos integrantes; d) Redes Burocráticas Assimétricas, nas quais há formalização legal, padronização de informações e serviços por meio de instrumentos legais mais rígidos que estabelecem exclusividades, direitos, controles e modo de transferência de conhecimento entre os integrantes. Franquias e Licenciamento de Marcas são exemplos típicos; e) Redes Proprietárias Simétricas, nas quais uma nova empresa é criada (caso das Joint Ventures), como forma de equilíbrio de forças entre as empresas integrantes, não necessariamente pela participação acionária igualitária, mas sob a forma de balanceamento de poderes, sem qualquer órgão regulador central. Predominam contratos formais e cláusulas que estabelecem acordos e direitos à propriedade dos integrantes; f) Redes Proprietárias Assimétricas, caracterizadas pela presença da empresa investidora que exerce a governança corporativa e liderança nos processos de inovação tecnológica, atividade motora do agrupamento. As empresas de capital de risco são típicas deste agrupamento.

\subsection{Interação e aprendizagem}

Os laços estabelecidos pelos integrantes de uma rede de cooperação formam canais exploratórios, 
conforme a definição de Matheus e Silva (2006), e exercem papel fundamental no desempenho da rede. Através dos laços flui conhecimento e aprendizado entre os integrantes, estabelecendo a difusão e adoção de inovações tecnológicas, conforme salienta Deroïan (2002). Granovetter (1985) tipificou os laços como: a) Ausentes, caracterizados como barreiras à expansão do conhecimento, exatamente pela lacuna de conexão; b) Fortes, caracterizados pela confiança mútua e a alta dose emocional entre integrantes. Ocorrem em empresas em que predominam vínculos familiares ou de amizade, conforme Lazzarini, Chaddad e Neves (2000). São fundamentais à confiança mútua, mas podem restringir a circulação de informação aos vínculos fortes, comprometendo a evolução do aprendizado; c) Fracos, fundamentais à circulação de novas informações. Segundo Granovetter (1985), são estes laços que preenchem os "buracos estruturais" de uma rede empresarial, ou seja, oportunidades de intermediação e ganho de conhecimento em função de lacunas existentes ("brokerage").

Borgatti e Croos (2003) classificam os laços quanto à sua natureza como sendo: a) Associativistas, quando os integrantes participam de mesmos eventos (associações, congressos, convenções, seminários, etc.); b) Biológicos, quando prevalece o grau de parentesco entre integrantes, como entre pai e filho; c) Formais, estabelecidos entre níveis hierárquicos empresariais ou sociais; d) Individuais, resultantes da amizade entre os atores; e) Interativos, criados quando interesses comuns e convergentes aproximam voluntariamente integrantes de uma rede; f) Transacionais, quando há transferências de bens ou recursos materiais; g) Transferenciais, quando há transferências de bens intangíveis na forma de serviços ou informações.

A combinação adequada entre a característica e a natureza dos laços definirá a eficiência dos canais exploratórios. Além desta combinação, também a heterogeneidade do conhecimento dentro da rede social favorecerá a ocorrência de laços fracos, mais adequados à capacitação e aos processos de aprendizagem dos integrantes. De fato, conforme Rodans e Galunic (2004), a heterogeneidade do conhecimento dos integrantes de uma rede social está diretamente relacionada ao desempenho adequado na gestão das operações e no processo de inovação. Os autores salientam que a combinação destes fatores proporciona a evolução nos processos de gestão da própria rede social e fortalece o desempenho gerencial dos integrantes pela acumulação de informações trocadas. Desta forma são estabelecidas as ações conjuntas, conforme destaca Carvalho (2009), estabelecendo a cooperação horizontal, frequente entre empresas de uma Rede Simétrica, e a cooperação vertical, mais frequente nas redes em que ocorre assimetria corporativa, tais como nas redes Burocráticas e Proprietárias. Isto aumenta o potencial de valor e o capital social dos integrantes, e fortalece o perfil empreendedor, conforme conclui Rodans e Galunic (2004).

A cooperação vertical ou horizontal estimula a evolução tecnológica do grupo, pois, conforme Karlsson (2003), a gestão da tecnologia acaba redundando na gestão do conhecimento, o que gera a necessidade de perspectivas mais amplas, que implicam a divisão de tarefas por meio dos laços de interação entre os integrantes de redes sociais.

Conforme Belussi e Arcangeli (1998), a eficiência dos canais exploratórios e o consequente fluxo do conhecimento e tecnologia definirão as formas de aprendizagem e frequências de interação, resultando nas redes de cooperação classificadas como: a) Estacionárias, em que a troca de informação limita-se aos integrantes, comprometendo a identificação de buracos estruturais que possibilitem ganhos e vantagens competitivas. Há restrição a novos conhecimentos e competências coletivas, pois predominam os laços fortes ou ausentes; b) Retráteis-reversíveis, em que ocorrem relações frequentes e dinâmicas entre os integrantes, capazes de incorporar conhecimentos adaptados às exigências da demanda; ocorrem com mais frequência os laços fortes ou ausentes, mas já ocorreram os laços fracos associativistas e interativos, fruto da vinculação com agentes externos; c) Evolucionárias, nas quais os integrantes são capazes de identificar buracos estruturais e associá-los às suas competências internas de modo a estabelecer intenso aprendizado, formação de competências coletivas e exploração das potencialidades; ocorre o aumento da escala aparente e geração de produtos. Podem ocorrer laços ausentes ou fortes, mas predominam os laços fracos interativos, transacionais e transferenciais, frutos da transferência intensa de bens materiais, recursos, serviços e informações. É a situação ideal para a evolução da rede social.

A interação das empresas dentro da rede de cooperação confrontará o aspecto "competição" com o fator "cooperação", fruto dos próprios laços de conexão dos integrantes. Conforme Loebbecke e Van Fenema (1998), o equilíbrio entre estas forças, determinantes do sucesso do processo de aprendizagem, evolução e geração de vantagens competitivas, irá definir o ambiente reinante, no qual poderão ocorrer: a) Sinergia, caracterizada pela adição potencial de valor que a troca de informações proporciona às partes envolvidas; b) nivelamento, caracterizado pela capacidade do receptor da informação de aumentar seu valor, pela exploração do conhecimento compartilhado, para além da relação de cooperação; c) impacto reverso-negativo, que resulta na redução de valor da parte emissora em função do uso da informação pela parte receptora. É um inibidor ao equilíbrio cooperação-competição. 


\subsection{Confiança versus comportamento oportunista}

Conforme Onyx e Bullen (2000), uma rede social é a organização na qual pessoas estabelecem conexões, normas, confiança social e coordenação, voltadas aos benefícios mútuos e à construção do "capital social" da rede de cooperação. Conforme Malafaia et al. (2007), é o capital social que estabelece a confiança mútua e a colaboração entre os integrantes. A confiança é o maior desafio à formação da rede, peça-chave para a cooperação, e, conforme Olave e Amato Neto (2001), estratégica ao sucesso da rede de cooperação. Por outro lado, Gulati (1995) associa o fator confiança ao comportamento oportunista entre os integrantes da rede, argumentando que, se a confiança é importante para o sucesso da rede, o comportamento oportunista será intrínseco à sua formação. $\mathrm{O}$ autor salienta que o temor ao comportamento oportunista estará presente em qualquer rede entre empresas, especialmente naquelas voltadas à $\mathrm{P} \& \mathrm{D}$, como é o caso das empresas de base tecnológica.

De fato, confiança e oportunismo estão estreitamente associados apesar de serem antagônicos. Conforme Gulati (1995), a confiança mútua pode se tornar um aspecto negativo quando se torna excessiva, limitando a percepção das empresas sobre comportamentos oportunistas, tornando-as vulneráveis. Ao mesmo tempo, o autor salienta que a ocorrência do comportamento oportunista entre duas empresas ocorre apenas uma vez. Quando ocorre, os laços se desfazem e raramente será estabelecida nova interação, perdendo-se oportunidades vantajosas. Assim, a importância estratégica da confiança reside não apenas no estabelecimento dos laços necessários à formação de canais exploratórios eficientes, mas também no estabelecimento da intensidade adequada desses laços, conforme Tálamo e Carvalho (2010). Conforme o autor, a aplicação de contratos que formalizem direitos e obrigações entre as partes, contribuem para o estabelecimento da confiança, tornando o comportamento oportunista um aspecto gerenciável ao invés de um entrave à rede. Conforme Uzzi e Gilespie (2002), redes que estabelecem a governança corporativa por meio de contratos ou acordos de equidade, garantem a transferência de conhecimentos e recursos entre os integrantes. Grandori e Soda (1995) argumentam que acordos de propriedade são instrumentos de coordenação que fortalecem as iniciativas de cooperação entre empresas de base tecnológica, em que a incerteza associada a atividades de $\mathrm{P} \& \mathrm{D}$ pode estimular comportamentos oportunistas. Ao estabelecerem acordos de propriedade antes mesmo dos resultados da pesquisa conjunta, estes instrumentos fortalecem o espírito cooperativo.

\section{Metodologia}

Dado o caráter exploratório dos objetivos da pesquisa, que visa compreender o processo de estruturação de uma rede de cooperação no contexto de empresas de base tecnológica, a metodologia utilizada foi a pesquisa-ação.

Busca-se criar conhecimento e teoria a partir da estruturação de uma rede de cooperação, aproximando ação e pesquisa, conforme sugerido por Coughlan e Coghlan (2002). Dentre os quatro tipos de pesquisa-ação definidos por Karvinen e Bennett (2006), denominados Diagnóstica, Empírica, Experimental e Participativa, aplicou-se a Pesquisa-ação Participativa, caracterizada pelo desenvolvimento de situações reais, junto a integrantes pré-selecionados, pela investigação e implantação de novas ferramentas de gestão, difusão de conhecimento e mudança cultural. Westbrook (1995) comenta que a pesquisa-ação pode superar deficiências de métodos tradicionais de pesquisa, que nem sempre interagem diretamente com os atores envolvidos.

Conforme Coughlan e Coghlan (2002), o ciclo da pesquisa-ação é formado por três fases distintas denominadas pré-análise, desenvolvimento e monitoramento.

A pré-análise, para fundamentação dos dados iniciais, foi executada conforme três dentre os nove aspectos salientados por Gummesson (2000 apud COUGHLAN; COGHLAN, 2002), detalhados a seguir:

1. Análise prévia do ambiente corporativo, por meio de visita preliminar a cada empresa pré-selecionada, levantamento de seu mix de produtos e identificação das necessidades, conforme estabelecido por Nonaka e Takeuchi (1995);

2. Abordagem holística do projeto, informando cada empresário sobre conceitos, dificuldades e vantagens da estrutura em rede de cooperação;

3. Atendimento a dois objetivos fundamentais: aumento dos ganhos financeiros das empresas e construção teórica das necessidades e ferramentas mais adequadas à gestão de uma rede de cooperação empresarial com empresas de base tecnológica.

O desenvolvimento da pesquisa-ação foi executado de acordo com o ciclo contínuo formado pelas seis etapas estabelecidas por Coughlan e Coghlan (2002), conforme a Figura 1.

A coleta de dados reúne informações necessárias ao desenvolvimento da etapa que se inicia. A realimentação dos dados compreende a análise prévia e realimentação das conclusões ao sistema cliente, no caso, os empresários representantes das empresas analisadas.

A análise dos dados é a etapa crítica da pesquisa-ação, na qual pesquisador e integrantes trabalham em conjunto, analisando os resultados obtidos, a fim de estabelecerem o plano de ação ou as ações a serem tomadas. A implantação é a 


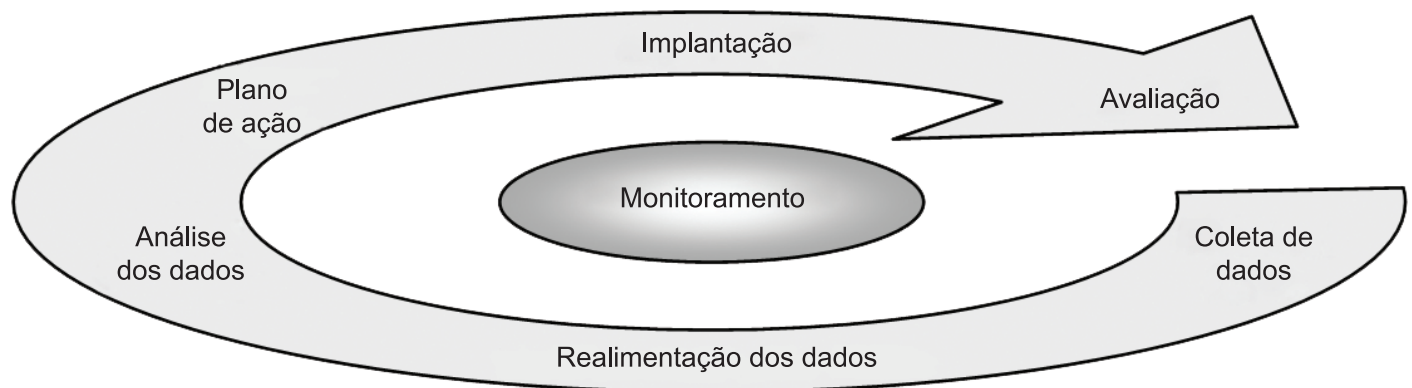

Figura 1. Ciclo e etapas da pesquisa-ação. Fonte: Elaborada pelos autores.

colocação em prática das ações escolhidas. A avaliação é a análise dos resultados obtidos e a revisão dos processos, para preparação do início de um novo ciclo, com base na experiência do ciclo anterior.

A execução de cada ciclo da pesquisa ocorreu conforme outros três, dentre nove aspectos salientados por Gummesson (2000 apud COUGHLAN; COGHLAN, 2002), conforme segue:

1. Coleta de dados por meio de entrevistas estruturadas e etnográficas, conforme a pesquisa tradicional, junto ao método de Saaty (1994) para apoio à decisão.

2. Atuação com estrita ética, valores e normas de conduta, trabalhando-se em todas as etapas com sigiloso e concordância prévia de cada empresário.

3. Atuação direta junto aos empresários pré-selecionados, identificando pontos com potencial, ou não, de compartilhamento.

O monitoramento ocorreu simultaneamente a todos os ciclos, para a construção do conhecimento. Nesta etapa, foram aplicados os demais três aspectos salientados por Gummesson (2000 apud COUGHLAN; COGHLAN, 2002), conforme abaixo:

- Atuação de modo participativo junto aos empresários, em todas as etapas;

- Busca da mudança da cultura organizacional, conforme reafirmado por Coghlan e Brannick (2001);

- Uso da experimentação e prática, por meio da atuação do pesquisador como agente facilitador, com perfil de consultoria.

Os trabalhos foram elaborados conforme a sequência de atividades proposta por Coughlan e Coghlan (2002) e o resultado esperado com o sucesso na formação da rede de cooperação era a melhoria do desempenho financeiro das empresas integrantes. A pesquisa-ação foi desenvolvida com um grupo de micro, pequenas e médias empresas pré-selecionadas, fabricantes de equipamentos e instrumentos eletrônicos voltados ao mesmo tipo de aplicação, ou seja, trata-se de cooperação entre concorrentes potenciais, mas dispostos a participar da experiência de formação da rede de cooperação. Com base nesses critérios, foi selecionada uma amostra inicial de 30 empresas do setor eletroeletrônico, estabelecidas na região geográfica da Grande São Paulo, para a pesquisa.

\section{Resultados da pesquisa}

$\mathrm{O}$ desenvolvimento da pesquisa compreendeu a execução de seis ciclos, cada um deles com as seis etapas definidas por Coughlan e Coghlan (2002). Por meio dos ciclos foi possível a identificação dos pontos fracos e fortes de cada empresa, cujo compartilhamento poderia gerar oportunidades e ganhos, mapeando-se as atividades de compartilhamento viáveis e identificando-se as ameaças à estruturação de uma rede de cooperação.

Os ciclos executados são descritos resumidamente a seguir.

$1^{\circ}$ Ciclo - Definição do tema: Neste ciclo, foi definida a metodologia, a pesquisa bibliográfica e a construção dos objetivos a serem buscados. Definiu-se o objetivo de estruturar a rede com empresas de base tecnológica, concorrentes diretas entre si, estabelecendo-se o desafio cultural, pois a formação de uma rede social com empresas desse perfil é pouco usual, principalmente se levarmos em conta as informações privilegiadas, relacionadas a desenvolvimentos e patentes. Neste ciclo foram identificadas: a) as empresas potencialmente participantes; b) a necessidade da ação; c) as forças atuantes; e d) a justificativa técnica da pesquisa.

$2^{\circ}$ Ciclo - Avaliação dos integrantes e levantamento dos problemas: Depois da seleção preliminar executada no $1^{\circ} \mathrm{Ciclo}$, foram contatados os atores primários, ou seja, os empresários com poder decisório, e foram expostos os conceitos básicos da formação da rede de cooperação, propondo-se visita técnica para exposição mais detalhada dos conceitos, vantagens, dificuldades e objetivos voltados aos ganhos de escala. Onze empresas não se enquadravam no foco da pesquisa, restando 19 empresas pré-selecionadas. A apresentação detalhada dos pontos fundamentais da estruturação em rede de cooperação foi elaborada 
conforme Amato (2000), com ênfase nos seguintes aspectos:

- Combinar competências e compartilhar o conhecimento tecnológico;

- Dividir o risco inerente à pesquisa tecnológica;

- Compartilhar o desenvolvimento e conhecimentos adquiridos;

- Dividir os riscos envolvidos na busca de novas oportunidades;

- Oferecer uma linha conjunta de produtos, diversificada e de melhor qualidade;

- Atuar mais agressivamente na prospecção do mercado, favorecendo o cliente;

- Compartilhar recursos produtivos ociosos;

- Fortalecer o poder de compra;

- Busca de mercados internacionais.

Neste ciclo, já se manifestaram os primeiros sinais contrários ao aspecto essencial à formação da rede: a confiança mútua. Quatro empresários, deduzindo que seus concorrentes diretos estariam no grupo, impuseram restrições às suas presenças. Apesar do nome das empresas ainda não ter sido divulgado, de fato, as quatro empresas objeto da restrição integravam o grupo das 19 empresas pré-selecionadas. Como os empresários manifestantes das restrições tinham maior porte e eram comercialmente mais fortes, optou-se por desligarem-se os quatro empresários, objetos da restrição. Um dos quinze empresários remanescentes solicitou a saída do grupo por questões organizacionais de sua empresa, reduzindo-se a quatorze o número de potenciais integrantes. A Tabela 1 indica o porte e os produtos principais das quatorze empresas remanescentes.

Por meio de entrevistas etnográficas, foram coletados os dados significativos e identificadas as atividades críticas, declaradas pelos empresários como pontos crônicos de problemas, conforme segue:

1. Caixas Plásticas fora de Padrão: Nove empresas compravam caixas plásticas de um mesmo fornecedor. As caixas plásticas são usadas na montagem dos instrumentos de medição tais como amperímetros e megômetros, os quais são instalados em painéis elétricos. O fornecedor das caixas plásticas é proprietário da ferramenta de injeção, cujo molde apresenta falhas dimensionais, obrigando os integrantes da pesquisa, a retrabalhar as bordas das caixas plásticas com limas ou lâminas de corte, para ajuste às dimensões dos painéis elétricos, conforme padrão internacional. A falha dimensional e o retrabalho resultam em acabamento superficial de baixa qualidade, dificultando a exportação dos instrumentos;

2. Baixa Carga de Ferramental: Em função do fato abordado acima, um dos empresários resolveu o problema pagando a confecção de ferramenta própria para injeção de suas caixas plásticas, dentro dos padrões dimensionais internacionais. O molde foi projetado para a injeção de caixas plásticas em ABS - Acrilonitrila Butadieno Estireno, blenda com boa estabilidade dimensional, acabamento superficial brilhante e alta resistência ao impacto. Com as características mais favoráveis do ABS, junto ao fato da peça estar dentro das dimensões, este fornecedor utilizava caixas de alta qualidade, produzidas por ferramenta própria, fabricadas em empresa de injeção plástica terceirizada, que vendia horas de máquina injetora. Como seu volume de consumo era inferior à capacidade produtiva da ferramenta, por estar voltado à solução (peças por encomenda) ao invés de commodities (larga escala), sua ferramenta era usada a cada seis meses, permanecendo ociosa entre os intervalos de uso. O tempo de amortização desta ferramenta será muito longo, tornando-a antieconômica;

3. Subutilização da Carga de Máquinas: A maior empresa do grupo em análise, apesar de ser classificada como de médio porte conforme padrões nacionais, é a maior do mercado nacional no segmento de instrumentação. Em função de seu porte, tem ferramentas e máquinas próprias para injeção de caixas plásticas, em condições ideais em termos de dimensões e resistência mecânica.

Esta empresa conta com uma unidade fabril voltada exclusivamente à injeção de peças plásticas, com um grupo de máquinas injetoras próprias. Neste caso, ocorre um fato similar ao do empresário descrito acima, porém referente às suas máquinas. Como a capacidade produtiva das injetoras é superior à demanda das caixas, mesmo com mix de produção próximo à commodity, suas máquinas trabalham apenas quatro horas por dia, permanecendo desligadas nas demais horas da jornada de trabalho. Este modo de operação gera elevado custo em termos de ociosidade, além de operação antieconômica relacionada ao desligamento e religagem diárias, com picos de consumo de energia elétrica e gasto de matéria-prima necessária à limpeza e regulagem das máquinas.

4. Produção em escala antieconômica: Esta situação ocorria com as empresas diametralmente opostas em seus portes. Tanto a maior do grupo (a mesma abordada acima) quanto a menor do grupo enfrentavam o mesmo problema e coincidentemente com o mesmo produto.

O proprietário da maior empresa comentou que era obrigado a parar a produção contínua de grandes lotes para a fabricação de pequenas quantidades de determinado produto, para atendimento a um grande cliente. Para atender um cliente com grande quantidade de um item, havia o compromisso comercial de fornecimento de outro produto em pequena escala, ou seja, a empresa voltada à produção seriada era obrigada a fornecer solução. As paradas de linha e trocas de material para a produção dos pequenos lotes reduziam a eficiência fabril. Ao mesmo tempo, a 
menor empresa do grupo atendia clientes compradores de pequenos lotes, fabricando o mesmo controlador "em bancada", ou seja, em produção artesanal. No caso da segunda empresa, o problema era relacionado à compra de componentes eletrônicos em pequena escala e preço mais elevado, tornando seu produto menos competitivo. Seu objetivo era fabricar lotes maiores, para otimizar as compras e utilizar sua mão de obra com mais eficiência;

5. Fabricação própria de fontes: A maior parte dos instrumentos eletrônicos analisados nesta pesquisa utiliza um componente denominado "fonte chaveada". Como o consumo destas fontes ocorre em baixa escala, cada empresa fabrica suas próprias fontes chaveadas, de modo artesanal. Isso resulta em fontes de grandes dimensões, sem padronização e custo mais elevado, em função da compra de componentes em pequena escala. Uma das empresas em análise tem subsidiária na China, onde produz fontes chaveadas padronizadas, de pequenas dimensões, baixo custo, de forma seriada e em larga escala. Esta empresa importa as fontes de sua subsidiária chinesa para montagem local de seus produtos;

6. Importação de caixas plásticas de diversos modelos: Algumas empresas importavam caixas plásticas de dimensões especiais, em volumes pequenos, em condição financeira desfavorável. Várias empresas tinham em seu portfólio produtos similares, utilizando o mesmo tipo de caixa, o que possibilitaria a importação conjunta;

7. Compra de componentes eletrônicos em baixa escala: Exceto as duas maiores empresas avaliadas, todos os demais empresários citaram problemas enfrentados com a compra de componentes em baixa escala, devido aos custos tributários de importação, o que compromete o custo final do produto. A compra dos componentes no mercado local elimina os impostos de importação, mas incorre em alto valor unitário. Neste caso, havia a possibilidade de importação conjunta, a preços mais competitivos e recolhimento de imposto uma única vez.

A obtenção dessas informações exigiu várias visitas e reuniões individuais com cada um dos empresários. Observou-se que a maioria dos problemas estava tão arraigada à cultura dos empresários que nem sempre eram vistos como problemas de fato e sim como situações normais da operação. O retrabalho de caixas plásticas, por exemplo, era encarado como inerente ao processo e não como atividade causadora de perdas de eficiência. Ao final desse ciclo, verificou-se que as possibilidades de compartilhamento eram reais e promissoras.

$3^{\circ}$ Ciclo - Avaliação do potencial de compartilhamento e divulgação dos nomes: $\mathrm{O}$ potencial de compartilhamento foi estabelecido em função dos problemas detectados no ciclo anterior e, nesta fase, foram divulgados os nomes das empresas, com a autorização prévia dos participantes.

Junto à análise de compartilhamento, procurou-se identificar as empresas de conhecimento estratégico, ou seja, aquelas que dominavam o processo de desenvolvimento de novos produtos, processos e ferramentais, e as de conhecimento técnico, ou seja, aquelas cujo conhecimento estava ligado ao processo operacional, como o aumento aparente da escala de produção.

Tabela 1. Porte e tipo de produto das empresas pré-selecionadas.

\begin{tabular}{|c|c|c|c|c|}
\hline \multirow[t]{2}{*}{ Empresa } & \multicolumn{3}{|c|}{ Porte } & \multirow[t]{2}{*}{ Produto } \\
\hline & $\mathbf{P}$ & M & G & \\
\hline A & & & $\mathrm{X}$ & Amperímetros, voltímetros, contadores digitais \\
\hline $\mathrm{B}$ & & $\mathrm{X}$ & & Painéis elétricos para siderúrgicas e empresas de energia \\
\hline $\mathrm{C}$ & & $X$ & & Termopares \\
\hline $\mathrm{D}$ & & $\mathrm{X}$ & & Controladores de temperatura e sensores de pressão para polímeros \\
\hline $\mathrm{E}$ & $\mathrm{X}$ & & & Registradores gráficos, temporizadores, multímetros \\
\hline $\mathrm{F}$ & & & $\mathrm{X}$ & Controladores de vazão, pressão, temperatura, velocidade \\
\hline G & & $\mathrm{X}$ & & Painéis de controle e automação para indústrias mecânicas \\
\hline $\mathrm{H}$ & & $\mathrm{X}$ & & Controladores, pressostatos e transmissores de pressão e nível \\
\hline I & & $X$ & & Terrômetro, pontes de Kelvin e Wheatstone, Ohmímetro, Meghômetro \\
\hline $\mathrm{J}$ & $\mathrm{X}$ & & & Transformadores de corrente, amperímetros e voltímetros \\
\hline $\mathrm{K}$ & & $\mathrm{X}$ & & Multímetro para temperatura, Duty Cicle, Peak Hold, Auto Hold \\
\hline $\mathrm{L}$ & & $\mathrm{X}$ & & Medidores de vazão, pressão, temperatura e nível \\
\hline M & $\mathrm{X}$ & & & Amperímetros e voltímetros sob encomenda \\
\hline $\mathrm{N}$ & $\mathrm{X}$ & & & Medidores de vibração \\
\hline $\mathrm{O}$ & $\mathrm{X}$ & & & Multímetros sob encomenda \\
\hline
\end{tabular}

Fonte: Elaborada pelos autores. 
O objetivo foi estabelecer atividades de compartilhamento coerentes com o perfil de conhecimento da empresa, atribuindo as tarefas de conteúdo inovador às empresas de domínio estratégico, e as tarefas operacionais às empresas de domínio técnico e/ou científico. Com isto, buscava-se proporcionar flexibilidade e agilidade aos integrantes, pela concentração de cada empresa em sua "competência interna" (core business). A concentração das empresas em sua melhor competência interna levaria à melhor divisão das atividades, abrindo possibilidades de terceirização e cooperação interempresarial, reforçando a relações que levam à rede de cooperação.

Os compartilhamentos identificados como viáveis para implantação em curto prazo foram:

1. Compartilhamento de ferramenta e máquina de injeção: O proprietário da ferramenta de injeção das caixas plásticas colocaria esta ferramenta na máquina injetora da maior empresa do grupo, cujas máquinas trabalhavam com ociosidade. As peças produzidas seriam vendidas aos demais integrantes, proporcionando:

- acerto dimensional das caixas plásticas, sem a necessidade de retrabalhos;

- economia na mão de obra utilizada no retrabalho;

- acesso ao mercado externo visto que o problema dimensional e estético estaria corrigido;

- melhoria significativa no acabamento externo dos produtos, com caixa de maior resistência;

- rapidez na amortização da ferramenta de injeção, por meio de ganhos adicionais por parte de seu proprietário, com a participação na venda das caixas aos demais;

- aumento aparente da escala de produção do fabricante de caixas plásticas. A quantidade adicional produzida se destinaria ao abastecimento de todos os demais integrantes e não apenas ao proprietário das máquinas injetoras. A maior empresa obteria faturamento marginal, com a otimização da carga das máquinas, compartilhando os ganhos com o proprietário da ferramenta;

- redução nos custos de operação de pelo menos uma das máquinas injetoras, com a redução de paradas, eliminando a necessidade de regulagens e limpezas frequentes na máquina de injeção;

- redução no custo da caixa plástica, pois o preço seria mais baixo que o praticado pelo fornecedor comum, conforme apurado.

2. Licenciamento de produto: Como a empresa de maior porte produzia alguns itens em baixa escala, similares aos produtos fabricados artesanalmente pela empresa de menor porte, havia oportunidade do fabricante de menor porte produzir instrumentos de menor escala para a empresa de maior porte, adicionando sua marca, conforme os acordos do tipo O\&M. Seria obtido aumento aparente de escala produtiva na micro empresa e aumento da eficiência de processo produtivo na média empresa com redução de paradas de processo para troca de produtos na linha de montagem, ou seja, a combinação solução e commodity. Esta proposta foi citada espontaneamente por ambos empresários, ainda na fase em que ambos não tinham conhecimento dos demais integrantes.

3. Compartilhamento de fontes chaveadas: Um dos empresários do grupo, proprietário da subsidiária na China, poderia fornecer as fontes chaveadas de sua empresa aos demais integrantes, visto que abastecia suas próprias linhas de montagem com as fontes chaveadas importadas de sua subsidiária. A fonte chaveada deste fabricante era de baixo custo, padronizada, de dimensões reduzidas e compatíveis com a miniaturização de produtos. Com isto, os demais empresários ficariam livres dessa produção artesanal, reduzindo a variedade de itens comprados em escalas reduzidas, aumentariam a qualidade de seus produtos e otimizariam a mão de obra interna. O médio empresário obteria aumento aparente de sua escala de produção enquanto os demais obteriam redução de custos em seus produtos, com melhoria significativa da qualidade;

4. Compartilhamento de estandes em feiras setoriais, contratação conjunta de espaço publicitário em revistas especializadas e compra conjunta de folhetos e folders publicitários.

Apesar de todos os empresários se conhecerem, praticamente não havia interação comercial entre as empresas; apenas três delas apresentavam pequeno vínculo comercial. O compartilhamento possibilitaria relações horizontais mais intensas, conforme a Figura 2.

Esta análise identificou quatro empresas "vértice" da formação, das quais surgiriam as melhores e mais imediatas oportunidades de compartilhamento.

Depois da análise destes dados, foi solicitada autorização para divulgação dos nomes, junto à proposta de agendamento da primeira reunião com os integrantes. Todos os empresários concordaram com a divulgação dos nomes. Porém, depois da divulgação ocorreu uma reação oposta à receptividade inicial da ideia de compartilhamento. Começaram os problemas mais intensos relacionados a temor ao comportamento oportunista.

Um dos empresários (fundamental ao compartilhamento) comunicou a saída imediata do grupo por haver entre os integrantes um empresário com o qual haviam ocorrido problemas de participação societária à época da fundação de uma empresa comum pelos pais de ambos, sócios à época. 


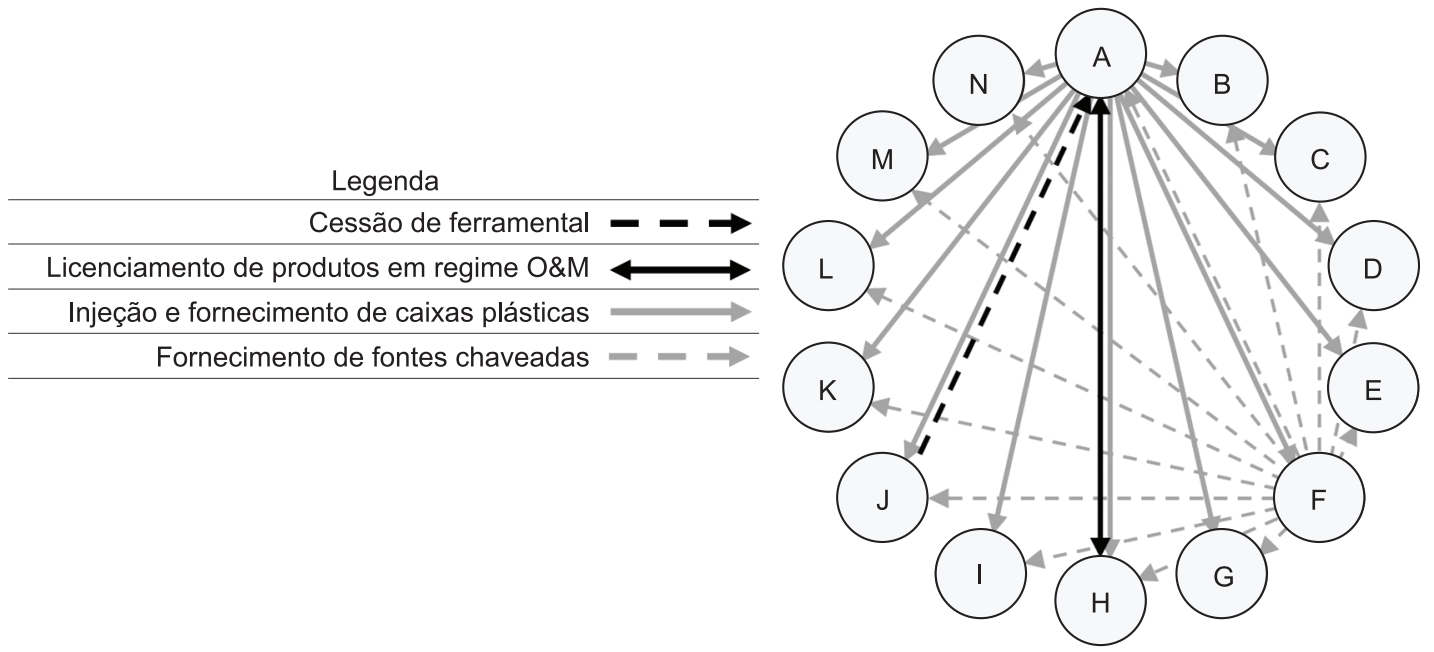

Figura 2. Possibilidades de conexões horizontais após a formação da rede de cooperação. Fonte: Elaborada pelos autores.

Outras empresas também manifestaram temores relacionados ao comportamento oportunista, mas não se desligaram de imediato; porém reduziram significativamente sua interação com o grupo, até o desligamento natural.

Oito empresas demonstraram interesse em levar adiante a proposta de formação da rede, as empresas C, E, G, H, J, K, M e N, conforme perfil caracterizado na Tabela 1.

Era esperada alguma reação relacionada ao aspecto confiança, porém não na intensidade demonstrada e depois do tratamento prévio dado às informações, durante a fase de abordagem individual dos empresários. O aspecto confiança apresentou impacto decisivo na continuidade dos trabalhos. A afirmação de Gulati (1995), de que a ocorrência do comportamento oportunista entre duas empresas ocorre apenas uma vez, desfazendo-se qualquer possível interação, com a perda de oportunidades vantajosas, foi claramente demonstrada.

$4^{\circ}$ Ciclo - Reunião do grupo e seleção das atividades de compartilhamento: Na primeira reunião entre os integrantes, foram reafirmados os princípios da cooperação empresarial e foi proposta a definição dos primeiros itens de compartilhamento, conforme Saaty (1994). Nesta reunião, foram detalhados os dados a serem coletados pelo preenchimento de questionários que indicassem os pontos fracos e fortes de cada empresa, apontados por seus respectivos representantes. A definição das primeiras atividades de compartilhamento seria elaborada a partir da tabulação dos dados coletados.

$5^{\circ}$ Ciclo - Avaliação dos dados, início e final das atividades: Os dados coletados no encerramento do $4^{\circ}$ ciclo foram avaliados conforme o processo de hierarquia analítica de Saaty (1994) e detalhado por Tálamo e Carvalho (2004), a fim de identificarem-se os pontos fortes e fracos de cada empresa e os pontos de maior oportunidade de compartilhamento. Junto a essa análise, foram identificados os pontos em que não haveria qualquer intenção de compartilhamento, para que nunca fossem abordados. A aplicação do método identificou a compra conjunta de componentes eletrônicos como a atividade de compartilhamento mais adequada para o início das atividades da rede de cooperação. A proposta era a consolidação das listas mensais de compras de cada integrante em uma única lista de componentes eletrônicos, com maior volume, possibilitando melhores condições de aquisição e tributação sobre uma única operação de aquisição. Entretanto, apesar do processo ter-se demonstrado adequado e de todas as informações referentes a vantagens e desvantagens da estruturação de uma rede de cooperação, apenas três empresários mostraram-se dispostos a levar adiante o processo de compras conjuntas. Houve resistência por parte dos empresários remanescentes; todos se mostraram resistentes à mudança cultural proposta no início dos trabalhos, mesmo com as fortes evidências de ganhos a serem proporcionados a todos os integrantes da pesquisa. Apesar de as listas de componentes eletrônicos serem compostas por produtos disponíveis no mercado, à exceção de alguns componentes ativos, a maioria dos integrantes mostrou-se insegura em revelar seu mix de compras, com receio de que isto pudesse revelar procedimentos de projeto e fabricação dos produtos acabados, informação considerada absolutamente sigilosa por parte dos empresários. A resistência cultural por parte dos integrantes da pesquisa dificultou a formação da rede de cooperação.

$6^{\circ}$ Ciclo: Avaliação das causas da falha junto aos integrantes: Coleta da opinião de integrantes 
remanescentes do grupo, para avaliação final e construção das conclusões desta pesquisa.

A principal barreira à formação da rede de cooperação foi o temor ao comportamento oportunista, manifestado desde as primeiras etapas do trabalho, comprometendo a possibilidade de formação dos laços de confiança. De fato, depois da divulgação dos nomes das empresas, um dos empresários fundamentais à formação solicitou o desligamento por temor ao comportamento oportunista de outra empresa, relacionado a fatos ocorridos há vários anos.

O temor ao comportamento oportunista está associado não apenas a aspectos pontuais, mas também decorre de aspectos ambientais, como a estrutura sociopolítica do País. Conforme um dos empresários entrevistados no $6^{\circ}$ ciclo da pesquisa, o problema da confiança decorre não apenas do comportamento dos integrantes. Ao ser questionado sobre as razões da não evolução do projeto da RCE, declarou:

A razão, declarada por um colega que estava no mesmo projeto, é que se for aberta a lista de componentes que nós compramos, isso indicará ao concorrente o caminho que a empresa percorreu para o desenvolvimento do produto. Dito textualmente por outro empresário [...]

Ao ser indagado se o aspecto "confiança" foi determinante à não formação da rede, respondeu que:

[...] a legislação brasileira obriga o pequeno empresário a pagar uma despesa fixa de $\mathrm{R} \$ 900,00$ por importação de componente eletrônico, seja uma importação de US\$100,00 ou uma importação de US $\$ 900,00$. As taxas são muito maiores que o valor da importação. Por essa razão, muitos são obrigados a fazer um caixa paralelo para trazer o componente. Através de compartilhamento, este aspecto pode se tornar público $[\ldots]$

[...] além disso, há outro aspecto que traz insegurança e desconfiança ao empresário brasileiro. É o problema da falta de um Sistema Judiciário sério, independente e que aja no tempo certo. Se o produto de um empresário é copiado integralmente e o empresário tiver que recorrer ao judiciário, quantos anos ele irá gastar até ter o seu direito comprovado? O Judiciário brasileiro se esconde atrás de leis de fachada. Enquanto não tivermos um judiciário ágil, crítico e sensível às falhas das próprias leis, nós sempre estaremos inseguros. O empresário brasileiro é totalmente inseguro [...]

Nesse sentido, a estrutura da rede mais adequada para esse agrupamento de empresas seria uma rede Burocrática Simétrica, sem a presença de hierarquia entre os integrantes, porém regidos por instrumentos legais que definissem deveres e obrigações além de estabelecer sanções aos que contrariassem os princípios fundamentais da confiança mútua.

De fato, desde o início dos trabalhos, a ocorrência da hierarquia foi recusada pelos empresários, principalmente pelo fato de serem empresas de base tecnológica, nas quais há o desenvolvimento individual de produtos. Entretanto, ficou clara a necessidade de um gestor central, com a atribuição de organizar e coordenar as decisões do grupo. Outro empresário entrevistado, entre os remanescentes do grupo, citou a falta de um gestor em tempo integral junto aos empresários como um dos entraves à formação da rede.

\section{Análise dos resultados}

O processo de estruturação da rede de cooperação, apesar de não ter chegado ao resultado esperado, forneceu novas evidências, além de confirmar dados teóricos. A pesquisa confirmou as afirmações de Grandori e Soda (1995), Gulati (1995) e Williamson (1998) segundo os quais, a cooperação é benéfica, mas muito difícil de ser estabelecida e mantida. Conforme Onyx e Bullen (2000), é na rede social que as pessoas estabelecem conexões, normas, confiança social e coordenação voltadas a benefícios mútuos.

De fato, as possíveis vantagens que seriam obtidas com a formação desta rede eram reais e de retorno imediato, conforme debatido nos dois primeiros ciclos da pesquisa. Nestes ciclos, foi possível identificar interesses fundamentais para a rede e o reconhecimento de que estes poderiam ser compartilhados, aproximando naturalmente os parceiros dessa rede em potencial.

No entanto, os indícios de falta de confiança e temor de comportamento oportunista surgiram inicialmente no $3^{\circ}$ Ciclo de pesquisa, em que se avaliaria o potencial de compartilhamento entre as empresas. Nesta fase, houve a retirada de um dos empresários por temor de comportamento oportunista de outro empresário da rede, devido à experiência negativa pregressa. Neste sentido, observou-se a pertinência da afirmação de Gulati (1995), de que basta o comportamento oportunista se manifestar apenas uma vez; quando ocorre, os laços se desfazem e dificilmente haverá possibilidade de interação futura, podendo-se desperdiçar oportunidades vantajosas. Em decorrência desse incidente, que parecia pontual entre dois empresários, mas que gerou um clima de temor que se espalhou rapidamente entre os demais, o número de empresários interessados caiu de quinze para oito, neste ciclo.

Nos ciclos seguintes, a sequela deixada pela retirada de parcela significativa dos empresários, com forte expectativa de comportamentos oportunistas por parte dos empresários levou à busca pela estruturação de contratos, cujo monitoramento envolvia custos de transação, conforme sugere Williamson (1998), proporcionais a essa expectativa de comportamentos oportunistas das partes contratantes. No limite, os custos de transação se tornaram tão elevados que inviabilizaram a assinatura de contratos entre as partes interessadas.

A estrutura da rede julgada mais adequada ao agrupamento foi a rede Burocrática Simétrica, sem a presença de hierarquia entre os integrantes, porém regidos por instrumentos legais com deveres 
e obrigações bem estabelecidos, além de sanções aos que contrariassem os princípios fundamentais da confiança mútua. Neste caso, o fator confiança seria tratado como um custo e incorporado aos instrumentos a fim de reger e dar previsibilidade ao comportamento dos parceiros, conforme sugerido por Uzzi e Gillespie (2002). Neste sentido, Gulati (1995) sugere considerar os seguintes aspectos para dimensionar os custos de transação: negociação, elaboração de contratos, estabelecimento de direitos e obrigações entre as partes. Destaca-se, portanto que vários desses aspectos estão condicionados ao grau de confiança entre as partes e impactam nos custos de transação (GULATI, 1995; WILLIAMSON, 1998; UZZI; GILLESPIE, 2002).

Além disso, não havia alianças prévias entre os empresários. Caso estas existissem, segundo Gulati (1995), seria possível utilizar-se progressivamente menos hierarquia na forma de coordenação, dada a confiança e familiaridade entre os parceiros transcendendo os aspectos formais e os custos derivados da desconfiança. Portanto, viu-se que os custos de transação seriam excessivos para as empresas envolvidas.

Aspectos ligados à confiança estão associados não apenas ao relacionamento entre os parceiros, mas também decorre de aspectos relativos à estrutura sociopolítica do País, conforme um dos empresários entrevistados no $6^{\circ}$ ciclo da pesquisa. Portanto, outro item crítico à formação da rede foi o caráter motivacional do agrupamento. Pode-se observar também que, o caráter motivacional, em oposição ao caráter volitivo, é um dado fundamental ao sucesso da rede, capaz de contrapor-se ao temor ao comportamento oportunista. Desse modo, o ideal seria a rede ter-se formado a partir do caráter motivacional e não por meio do caráter volitivo, baseado apenas no impulso do comportamento voluntário a uma ação, como ocorreu nesta pesquisa. Outras ações de compartilhamento poderiam surgir com o consequente amadurecimento dos integrantes quanto ao aspecto cooperação. Apesar do maior entrave ao processo ter sido de ordem cultural, Panetto e Molina (2008) salientam que o futuro empresarial reside nos canais de cooperação entre empresas, pessoas e sociedades, a fim de serem compartilhados os conhecimentos, e destacam o compartilhamento como uma das áreas estratégicas.

Quanto ao uso da pesquisa-ação, observou-se que o método apresenta de fato as vantagens apontadas pelos diversos autores (WESTBROOK, 1995; COGHLAN; BRANNICK, 2001; COUGHLAN; COGHLAN, 2002; KARVINEN; BENNETT, 2006), como discutido anteriormente. No entanto, observou-se a mesma dificuldade apontada por Miguel (2008), a necessidade de imparcialidade dos pesquisadores na intervenção realizada, o que demanda autodisciplina. Apesar de ser uma preocupação da equipe na condução da pesquisa, o clima estabelecido entre os membros da rede a partir do $3^{\circ}$ ciclo da pesquisa, por vezes, chegava à equipe de pesquisadores na forma de demanda por posicionamento em face dos conflitos, ou ainda na busca de que a equipe assumisse papel de negociação entre os parceiros, o que demandou muita autodisciplina e cuidado por parte da equipe, para evitar essas armadilhas.

\section{Conclusões}

Não é só nos casos de sucesso que se tiram evidências importantes; nos casos de fracasso é possível refletir sobre fatores essenciais para o estabelecimento de bases futuras para a cooperação, tema fundamental para as empresas que querem inovar.

Esse estudo foi rico em elucidar o quanto a vontade de cooperar, apesar de condição necessária, não é suficiente para erguer os pilares de uma rede de cooperação empresarial. A confiança entre os parceiros da rede e a trajetória de cooperação mostraram aspectos críticos e intransponíveis, apesar dos cuidados metodológicos que balizaram todo o processo, e mecanismos contratuais estudados na formalização da rede. Neste sentido, essa pesquisa-ação trouxe os principais elementos necessários para discutir as questões centrais de pesquisa.

Apesar de a rede não ter se firmado, foram estabelecidas parcerias pontuais entre alguns dos membros da rede inicial a partir dessa pesquisa, que podem ser o embrião de uma futura rede de cooperação, construída em uma base temporal e a partir de experiências prévias mais consolidadas, transpondo as dificuldades iniciais.

Embora adequada para o tipo de pesquisa desenvolvida, em que se buscava envolvimento em profundidade nas questões de pesquisa, a adoção da pesquisa-ação lhe impôs algumas dificuldades e limitações. Houve preocupação constante com a imparcialidade da equipe de pesquisadores, mas, por vezes, os conflitos entre os membros transbordava para a equipe de pesquisadores, que precisava de autodisciplina para evitar um posicionamento, o que poderia afetar de forma significativa os resultados. Como limitação, destaca-se que, por se tratar de uma única rede de cooperação, os resultados não podem ser generalizados, mas mostram indícios relevantes, que, em grande parte, corroboram com a literatura apresentada.

Os achados da pesquisa colocam luz sobre o processo de construção da confiança e dos tradeoffs entre o temor de comportamento oportunista e os custos de transação, o que constitui uma agenda futura de pesquisa.

\section{Referências}

AMATO, J. N. Redes de Cooperação Produtiva e Clusters Regionais: Oportunidades para as pequenas e médias empresas. São Paulo: Atlas, 2000.

BELUSSI, F.; ARCANGELI, F. A typology of networks: flexible and evolutionary firms. Research Policy, v. 27 , p. 415-428, 1998. http://dx.doi.org/10.1016/ S0048-7333(98)00074-2 
BORGATTI, S. P.; CROOS, R. A Relational View of Information Seeking and Learning in Social Networks. Management Science, v. 49, n. 4, p. 432-445, 2003. http://dx.doi.org/10.1287/mnsc.49.4.432.14428

CARVALHO, M. M. et al. Fatores Críticos de Sucesso em Empresas de Base Tecnológica. Revista Produto \& Produção, v. 4, p. 47-59, 2000.

CARVALHO, M. M. Inovação: estratégia e comunidades de conhecimento. São Paulo: Editora Atlas, 2009. 161 p.

COGHLAN, D.; BRANNICK, T. Doing Action Research in Your Own Organization. London: Sage, 2001.

COUGHLAN, P.; COGHLAN, D. Action Research for Operation Management, International Journal of Operation \& Production Management, v. 22, n. 2, p. 220-240, 2002.

DEROÏAN, F. Formation of social networks and diffusion of innovations. Research and Policy, v. 31, p. 835-846. 2002.

FUSCO, J. P. A. et al. Redes Produtivas e Cadeias de Fornecimento. São Paulo: Arte \& Ciência, 2005.

GRANDORI, A.; SODA, G. Inter-firm Networks: Antecedents, Mechanisms and Forms. Organization Studies, v. 16, n. 2, p. 183-214, 1995. http://dx.doi. org/10.1177/017084069501600201

GRANOVETTER, M. Economic Action and Social Structure: The Problem of Embeddedness. American Journal of Sociology, v. 91, p. 481, 1985. http://dx.doi. org/10.1086/228311

GULATI, R. Does familiarity breed trust? The implications of repeated ties for contractual choice in alliances. Academy of Management Journal, v. 38, n. 1, p. 85-112, 1995. http://dx.doi.org/10.2307/256729

KARLSSON, C. The Development of Industrial Networks - Challenges to operations management in an extraprise. International Journal of Operations \& Production Management, v. 23, n. 1, p. 44-61, 2003. http://dx.doi. org/10.1108/01443570310453253

KARVINEN, K.; BENNETT, D. Enhancing performance through the introduction of customer orientation into the building components industry. International Journal of Productivity and Performance Management, v. 55, n. 5, p. 400-422, 2006. http:// dx.doi.org/10.1108/17410400610671435

LAZZARINI, S. G.; CHADDAD, F. R.; NEVES, M. F. O Conceito de capital social e aplicações para desenvolvimento e estratégia sustentável. Pesquisa Agrícola, p. 10-14, 2000.

LOEBBECKE, C.; VAN FENEMA, P. Towards a Theory of Inter-organizational Knowledge Sharing during Co-opetition. In: EUROPEAN CONFERENCE ON IS, 1998, Aix-en-Provence. Proceedings... Aix-en-Provence, 1998.

MALAFAIA, G. C. et al. Capital Social e a Construção da Confiança em Redes de Cooperação: Mudando padrões de relacionamento na pecuária de corte. In: ENCONTRO DA ASSOCIAÇÃO NACIONAL DE PÓS-GRADUAÇÃO E PESQUISA EM ADMINISTRAÇÃO - EnANPAD, 31., 2007, Rio de Janeiro. Anais... Rio de Janeiro: ANPAD, 2007.

MATHEUS, R. F., SILVA, A. B. O. Análise de redes sociais como método para a Ciência da Informação. Revista de Ciência da Informação, v. 7 n. 2, 2006.
MIGUEL, P. A. C. QFD no desenvolvimento de novos produtos: um estudo sobre a sua introdução em uma empresa adotando a pesquisa-ação como abordagem metodológica. Produção, v. 19, n. 1, p. 105-128, 2009. http://dx.doi.org/10.1590/S0103-65132009000100008

MUNIZ, S. Sambando em Gelo Fino - Investimento industrial, capacitação tecnológica e organizacional e competitividade brasileira nos anos 90. 2000. Tese (Doutorado em Engenharia de Produção)-Escola Politécnica, Universidade de São Paulo, São Paulo, 2000.

NONAKA, I.; TAKEUCHI, H. The Knowledge-Creating Company. New York: Oxford University Press, 1995.

OLAVE, M. E. L.; AMATO NETO, J. Redes de Cooperação Produtiva: Uma estratégia de competitividade e sobrevivência para pequenas e médias empresas. Gestão \& Produção, v. 8, n. 3, p. 289-303, 2001.

ONYX, J.; BULLEN, P. Measuring Social Capital in Five Communities. Journal of Applied Behavioral Science, v. 36, p. 23, 2000. http://dx.doi. org/10.1177/0021886300361002

PANETTO, H.; MOLINA, A. Enterprise integration and interoperability in manufacturing systems: Trends and issues. Computers in Industry, v. 59, p. 641-646. 2008. http://dx.doi.org/10.1016/j.compind.2007.12.010

PORTER, M. E. The competitive advantage of nations. New York: Free Press, 1990.

RODANS, S.; GALUNIC, C. More than network structure; how knowledge heterogeneity influences managerial performance and innovativeness. Strategic Management Journal, v. 25, p. 541-562.

SAATY, T. L. How to make a decision - The Analitic Hierarchy Process. Interfaces, v. 24, n. 6, p. 19-43, 1994.

SCOTT, A.; STORPER, M. Indústria de alta tecnologia e desenvolvimento regional; uma crítica e reconstrução teórica. Espaço e debates, v. 8, n. 25, p. 30-43, 1988.

STORPER, M.; HARRISON, B. Flexibility, hierarchy and regional developments: the changing structure of industrial production systems and their forms of governance in the 1990s. Research Policy, v. 20, n. 5, 1991.

TÁLAMO, J. R.; CARVALHO, M. M. Seleção dos objetivos fundamentais de uma rede de cooperação empresarial. Gestão \& Produção, v. 11, n. 2, p. 1-20, 2004.

TÁLAMO, J. R.; CARVALHO, M. M. Redes de cooperação com foco em inovação: um estudo exploratório. Gestão \& Produção, v. 17, n. 4, p. 747-760, 2010.

TÁLAMO, J. R. Formação e gestão de redes de cooperação empresarial. 2008. 233 f. Tese (Doutorado em Engenharia de Produção)-Escola Politécnica, Universidade de São Paulo, São Paulo, 2008.

UTTERBACK, J.; Mastering the Dynamics of Innovation. Boston: Harvard, 1994.

UZZI, B.; GILESPIE, Knowledge Spillover in Corporate Financing Networks: Embeddedness and the firm's performance. Strategic Managemente Journal, v. 23, p. 595-618, 2002. http://dx.doi.org/10.1002/smj.241

WESTBROOK, R. Action research, a new paradigm for research in production and operations management. International Journal of Operations \& Production Management, v. 15, n. 12, p. 6-20, 1995. http://dx.doi. org/10.1108/01443579510104466

WILLIAMSON, O. E. The Economic Institution of Capitalism. New York: The Free Press, 1998. 